\title{
Estudo do comportamento da aderência e do conforto ao rolamento em pistas de pouso e decolagem
}

\author{
Francisco Heber Lacerda de Oliveira ${ }^{1}$, Lucas Cavalcante de Almeida ${ }^{2}$ e Saulo Passos Ramos ${ }^{3}$
}

\begin{abstract}
Resumo: Este artigo analisa as relações existentes entre a aderência e o conforto ao rolamento em pistas de pouso e decolagem. Por intermédio dos dados de macrotextura, de coeficiente de atrito e do índice de irregularidade internacional, obtidos entre 2013 e 2014 no Aeroporto Internacional de Fortaleza, foi possível comparar esses parâmetros e suas alterações ao longo da pista. As análises foram efetuadas com base na literatura técnico-científica e nas exigências normativas da Organização da Aviação Civil Internacional e da Agência Nacional de Aviação Civil. Verifica-se que em alguns trechos da pista em estudo, sobretudo no segmento central, o comportamento entre os parâmetros analisados apresenta tendência divergente. Com esta análise, espera-se contribuir para o incremento da segurança das operações de pousos e decolagens, especialmente na resistência à derrapagem, no controle direcional e no conforto ao rolamento das aeronaves.
\end{abstract}

Palavras-chave: aderência, conforto, rolamento, pistas de pouso e decolagem, segurança.

Abstract: This paper analyzes the relationship between the grip and ride comfort on the runways. Through data of macrotexture, coefficient of friction and international roughness index, obtained between 2013 and 2014, it was possible to compare the parameters and their changes along the runway. The analyzes were based on technical and scientific literature and regulatory requirements of the International Civil Aviation Organization and the National Civil Aviation Agency. It notes that in some sections of the runway, especially in the central segment, the behavior of the parameters analyzed present divergent trend. With this analysis, we hope to contribute to enhancing the safety operations performance, especially in the skid resistance, the directional control and ride comfort of the aircraft.

Keywords: adherence, comfort, riding, runways, safety.

\section{INTRODUÇÃO}

Segurança deve ser prioridade absoluta em todas as operações de pousos e decolagens, pois são nessas operações que se concentram grande parte das ocorrências de acidentes ou incidentes envolvendo aeronaves. Assim, para evitá-las e aumentar a segurança das operações em solo, uma das soluções é investir na manutenção das condições físicas das pistas.

De acordo com CENIPA (2015), entre 2004 e 2014, cerca de $40 \%$ dos acidentes que envolveram aeronaves no Brasil, $15 \%$ ocorreram na fase de pouso, $7 \%$ na corrida após o pouso e $18 \%$ na decolagem, totalizando 457 acidentes no período. Estatísticas da Boeing (2014) mostram que dos acidentes fatais envolvendo operações de aeronaves comerciais a jato, entre 1959 e 2013, cerca de $23 \%$ ocorreram no pouso.

Na visão da FAA (2014), a manutenção é um processo contínuo e de responsabilidade crítica dos operadores de aeródromos. Planos de manutenção que produzam efeitos permanentes requerem uma série de inspeções periódicas e controladas. Essas avaliações são imprescindíveis quando se tratam das pistas de pouso e decolagem. Por isso, deve ser despendida uma atenção especial às condições de aderência entre os pneus das aeronaves e o revestimento dessas pistas.

\footnotetext{
1 Francisco Heber Lacerda de Oliveira, Departamento de Engenharia de Transportes, UNIFOR. (heberoliveiracivil@gmail.com)

2 Lucas Cavalcante de Almeida, Departamento de Engenharia de

Transportes, UFC. (lucasceara00@gmail.com)

${ }^{3}$ Saulo Passos Ramos, Departamento de Engenharia de Transportes,

UFC. (saulo0683@gmail.com)
}

Manuscrito recebido em 11/01/2016 e aprovado para publicação em 01/07/2016

Este artigo é parte de TRANSPORTES v. 24, n.2, 2016. ISSN: 2237-1346 (online). DOI:10.4237/transportes.v24.i2/1059
A macrotextura e o coeficiente de atrito são os principais parâmetros mensurados pelos operadores de aeródromos, regulados e fiscalizados pelas autoridades aeronáuticas, que visam a garantia da resistência à derrapagem, por meio da aderência pneu-pavimento. Nesse sentido, tem-se buscado desde dezembro de 2012 melhores condições operacionais nas pistas dos aeroportos brasileiros baseadas no atendimento adequado de outros parâmetros físicos, dentre os quais pode-se destacar a irregularidade longitudinal.

É notório que esses três parâmetros - macrotextura, coeficiente de atrito e irregularidade longitudinal - podem favorecer a segurança das operações de pousos e decolagens, por meio da melhoria da resistência à derrapagem, do controle direcional das aeronaves e do seu conforto ao rolamento. De algum modo, estão relacionados entre si à medida que são influenciados pela rugosidade dos revestimentos das pistas.

Neste artigo, procurar-se-á avaliar os parâmetros em relação aos índices de macrotextura, de coeficiente de atrito e de irregularidade longitudinal previsto nas normas brasileiras. Essa análise dar-se-á na pista de pouso e decolagem do Aeroporto Internacional de Fortaleza, Estado do Ceará, para os parâmetros obtidos entre 2013 e 2014 fundamentado nos respectivos ensaios e levantamentos específicos que serão descritos posteriormente.

\section{REVISÃO DA LITERATURA}

Para a FAA (2009), os pavimentos aeroportuários são construídos para fornecer suporte adequado às cargas impostas pelas aeronaves e para produzir uma superfície estável e suave ao rolamento. Alinhada a essa visão, assim como de ICAO (2004) e de Thom (2010), os principais requisitos de projeto e operação para pavimentos de aeropor- 
tos são aqueles relacionados a limitar a deformação da estrutura, a garantir uma adequada resistência à derrapagem e a evitar os danos às aeronaves.

Ao longo de todo o século 20 diversas pesquisas foram conduzidas e alguns conceitos relacionados à aderência entre pneus e superfícies de pavimentos foram apresentados. De acordo com ICAO (2012), no início de 1950, os requisitos de aderência foram discutidos, incluindo a necessidade de garantir que os revestimentos das pistas possuíssem características de atrito de modo a proporcionar frenagens eficientes.

Com a introdução de aeronaves turbojato, com grandes velocidades de deslocamento, o desempenho da frenagem sobre os pavimentos, segundo FAA (1997), tornou-se ainda mais crítico. Sob certas condições, aquaplanagens ou perdas de contato dos pneus das aeronaves com o pavimento podem ocorrer, resultando no desempenho deficiente da frenagem com possíveis perdas de controle direcional das aeronaves.

Thom (2010) assegura que a ausência da resistência à derrapagem é um problema crítico de segurança em pavimentos aeroportuários. Dessa forma, os índices da pista referentes à textura devem ser avaliados com regularidade e, particularmente, em condições climáticas adversas. As superfícies das pistas de pouso e decolagem devem ser suficientemente texturizadas e possuírem alta resistência à derrapagem.

ICAO (2002) e Kazda e Caves (2007) afirmam que a textura das superfícies das pistas de pouso e decolagem é caracterizada pela microtextura e pela macrotextura. Para Transport Canada (2004), ambas as características de microtextura e macrotextura afetam significativamente os valores de coeficiente de atrito medidos nas pistas de pouso e decolagem, constituindo-se em pré-requisitos essenciais para a manutenção de níveis satisfatórios de atrito.

A microtextura, segundo Piarc (1987), é função específica da superfície dos agregados, cuja aspereza proporciona atrito nas operações de baixas velocidades, como nos taxiamentos das aeronaves após os pousos. A macrotextura, formada pelo conjunto ligante e agregados, por sua vez, proporciona, segundo ICAO (2002), maior drenagem da água presente na superfície das pistas de pouso e decolagem. Para Fonseca (1990), a macrotextura reduz a tendência de os pneus das aeronaves experimentarem o fenômeno da aquaplanagem, especialmente para as altas velocidades desenvolvidas durante as operações de pousos e decolagens.

Dada a importância da macrotextura na drenagem ativa da água da superfície dos pavimentos aeroportuários, Oliveira e Nobre Júnior (2009) ressaltam a preocupação com a conservação permanente das pistas de pouso e decolagem com relação à impregnação de contaminantes.

Um dos elementos que mais prejudica a drenagem superficial do pavimento é a borracha proveniente dos pneus das aeronaves, uma vez que esse material pode preencher a profundidade da macrotextura e, dessa forma, não permitir o adequado escoamento da água, favorecendo os eventos de aquaplanagem. Nesse sentido, ANAC (2012a) alerta para a remoção do acúmulo de borracha, de acordo com a quantidade de pousos diários.

O propósito da avaliação periódica da resistência à derrapagem de um pavimento aeroportuário, na visão de
Sun, Kan e Ji (2004), é contribuir para a redução dos acidentes envolvendo saídas inesperadas das pistas de pouso e decolagem, por derrapagens, e apresentar recomendações para o aumento da capacidade de atrito. Informações da ICAO (2002) mostram que os incidentes e acidentes relacionados à saída ou à derrapagem de aeronaves durante pousos e decolagens, indicam que, na maioria dos casos, a causa principal, ou pelo menos um dos fatores contribuintes, foram as características de atrito sobre a eficácia dos freios das aeronaves.

Além da verificação das condições de aderência, a ANAC (2012b) recomenda, a partir de 2012, que os operadores de aeródromos brasileiros avaliem periodicamente a condição funcional das pistas de pouso e decolagem. Essa atividade consiste em executar a medição da irregularidade longitudinal e sua respectiva classificação, seguindo a escala do International Roughness Index - IRI.

Na definição de Sayers e Karamihas (1998), a irregularidade longitudinal é o somatório dos desvios da superfície de um pavimento em relação a um plano de referência ideal, considerando o projeto geométrico. Essa irregularidade afeta a dinâmica dos veículos e das cargas, a qualidade ao rolamento e a drenagem superficial da via. Assim, o IRI é um índice estatístico, expresso em $\mathrm{m} / \mathrm{km}$, que quantifica os desvios da superfície do pavimento em relação à de projeto.

Thom (2010) afirma que superfícies de pavimentos aeroportuários com IRI menor que $2,0 \mathrm{~m} / \mathrm{km}$ estão em condição excelente e maior que $5,0 \mathrm{~m} / \mathrm{km}$, muito acidentado/irregular. Para Gillespie, Sayers e Segel (1980), uma medida objetiva da irregularidade longitudinal pode servir para monitorar o estado geral dos pavimentos e apresentar um histórico de desempenho. O resultado desse monitoramento pode ser utilizado na avaliação de projetos alternativos de construção e manutenção.

Para aeroportos não há indicação de equipamentos de medição do IRI por parte da ICAO. No Brasil, a ANAC (2012b) também não recomenda um equipamento específico, mas afirma que o operador do aeródromo deve monitorar a irregularidade longitudinal por meio de medições, com equipamentos que permitam a obtenção de valores expressos no IRI. Trabalhos recentes como o de Almeida (2015) mostram que o IRI tem sido medido nos aeroportos brasileiros com o uso de perfilômetro inercial a laser.

Ainda no cenário dos aeroportos, ICAO (2004) recomenda que a superfície das pistas de pouso e decolagem deve ser mantida conservada de modo a impedir a formação de irregularidades prejudiciais que causem vibrações excessivas no controle direcional das aeronaves. Pequenos desvios acima do tolerado não interferem nas operações das aeronaves. Informações exatas do desvio máximo aceitável não podem ser fornecidas, ainda segundo ICAO (2004), pois isso varia com o tipo e a velocidade das aeronaves.

No Brasil, ANAC (2012b) adverte que o operador do aeródromo deve manter o IRI da pista de pouso e decolagem menor ou igual a 1,0m para cada extensão de $500 \mathrm{~m}$ de superfície avaliada, atendendo ao padrão apresentado por Sayers e Karamihas (1998). Vale ressaltar que não há indicação para medição em pistas de taxiamento ou pátios de estacionamento de aeronaves. 
Tabela 1. Profundidade média da macrotextura (mm) 2013

\begin{tabular}{c|c|c|c|c|c|c|c|c}
\hline $\begin{array}{c}\text { Trecho da pista } \\
(\mathbf{k m})\end{array}$ & \multicolumn{9}{|c|}{ Lado Esquerdo } & \multicolumn{4}{c}{ Lado Direito } \\
\cline { 2 - 10 } & Fev & Mai & Ago & Nov & Fev & Mai & Ago & Nov \\
\hline $0-0,5$ & 0,99 & 0,88 & 0,89 & 0,87 & 0,99 & 0,88 & 0,80 & 0,84 \\
\hline $0,5-1,0$ & 1,00 & 0,86 & 0,92 & 0,97 & 0,96 & 1,04 & 0,81 & 0,85 \\
\hline $1,0-1,5$ & 1,04 & 1,18 & 0,97 & 0,98 & 0,99 & 1,08 & 0,85 & 0,94 \\
\hline $1,5-2,0$ & 0,95 & 0,79 & 0,88 & 0,83 & 0,88 & 0,84 & 0,79 & 0,80 \\
\hline
\end{tabular}

Tabela 2. Profundidade média da macrotextura $(\mathrm{mm})-2014$

\begin{tabular}{c|c|c|c|c|c|c|c|c}
\hline \multirow{2}{*}{$\begin{array}{c}\text { Trecho da pista } \\
(\mathbf{k m})\end{array}$} & \multicolumn{9}{|c|}{ Lado Esquerdo } & \multicolumn{4}{c}{ Lado Direito } \\
\cline { 2 - 10 } & Fev & Mai & Ago & Nov & Fev & Mai & Ago & Nov \\
\hline $0-0,5$ & 0,79 & 0,90 & 0,85 & 0,93 & 0,74 & 0,85 & 0,74 & 0,95 \\
\hline $0,5-1,0$ & 0,70 & 0,88 & 0,64 & 1,12 & 0,69 & 0,85 & 0,72 & 0,89 \\
\hline $1,0-1,5$ & 0,89 & 0,91 & 0,96 & 1,32 & 0,87 & 0,88 & 0,81 & 0,96 \\
\hline $1,5-2,0$ & 0,73 & 0,84 & 0,66 & 0,83 & 0,65 & 0,77 & 0,61 & 0,89 \\
\hline
\end{tabular}

\section{METODOLOGIA DE OBTENÇÃO DOS DADOS}

Os dados de macrotextura, coeficiente de atrito e IRI foram obtidos na pista de pouso e decolagem do Aeroporto Internacional de Fortaleza. Para tanto, cumpriu-se os procedimentos recomendados e as práticas vigentes nas legislações nacionais expedidas pela Agência Nacional de Aviação Civil (ANAC).

\subsection{Macrotextura}

Apesar de existirem ensaios recomendados por ICAO (2002) e FAA (1997), a medição da macrotextura em pavimentos aeroportuários tem ocorrência mais frequentes, no Brasil, pela aplicação do ensaio da mancha de areia, conforme descrição de ANAC (2012a). O valor recomendado para a profundidade média da macrotextura deve ser maior ou igual a $0,60 \mathrm{~mm}$ para cada terço de extensão de pista. As medições devem ocorrer em toda a extensão operacional da pista de pouso e decolagem, em áreas onde não existam groovings, localizadas a 3,0m do eixo, de forma alternada a cada 100m, à direita e à esquerda, e com, no mínimo, 3 medições para cada área. A frequência mínima dessas medições ocorre em função da quantidade de pousos diários por cabeceira da pista, com periodicidades que podem variar de 30 a 360 dias.

No Aeroporto Internacional de Fortaleza, considerando a média de pousos diários anuais, tem-se a frequência mínima de medições da profundidade média da macrotextura a cada 90 dias, sendo obtidas nos meses de fevereiro, maio, agosto e novembro de 2013 e 2014, cujos valores são apresentados nas Tabelas 1 e 2, para trechos de $500 \mathrm{~m}$.

Os trechos indicados nas Tabelas 1 e 2 não correspondem a um terço da pista em estudo, conforme indica ANAC (2012a); o mesmo ocorrerá na exposição dos dados de coeficiente de atrito, no próximo subitem deste artigo. Contudo, os dados foram avaliados dessa forma para facilitar a análise comparativa com o IRI, que deve ser obtido para segmentos de $500 \mathrm{~m}$. Nesse caso, apenas os $2.000 \mathrm{~m}$ iniciais, a partir da cabeceira predominante, foram analisados, para fins de comparação entre os parâmetros e padronização dos segmentos da pista. No entanto, a pista foi toda avaliada quanto à profundidade média da macrotextura.

\subsection{Coeficiente de Atrito}

Quanto à obtenção do coeficiente de atrito, os valores mínimos e de manutenção são indicados por ANAC (2012a) em função do tipo de equipamento utilizado, do tipo e pressão dos pneus e da velocidade do ensaio, a uma espessura da lâmina de água simulada de $1,0 \mathrm{~mm}$. A localização dessas medições ocorre de modo contínuo a $3,0 \mathrm{~m}$ ou a $6,0 \mathrm{~m}$ do eixo da pista, a direita e a esquerda em toda sua extensão, em função do porte das aeronaves que operam no aeroporto. A frequência mínima dessas medições também ocorre em função da quantidade de pousos diários por cabeceira da pista, com periodicidades que podem variar de 7 a 360 dias.

Considerando as operações do Aeroporto Internacional de Fortaleza, a obtenção dos dados de coeficientes de atrito é feita, também, a cada 90 dias, nos mesmos meses de medição da profundidade média da macrotextura. Os dados de coeficiente de atrito para a pista de pouso e decolagem do Aeroporto Internacional de Fortaleza são apresentados nas Tabelas 3 e 4, igualmente à profundidade média da macrotextura, esses valores foram obtidos para trechos de $500 \mathrm{~m}$. A Tabela 5 apresenta as médias dos valores de atrito dos lados esquerdo e direito de 2013 e 2014. O objetivo de se trabalhar com essas médias é facilitar a análise do comportamento da pista de pouso e decolagem em relação ao coeficiente de atrito.

\subsection{Irregularidade Longitudinal}

A medição do IRI nos aeroportos brasileiros, por exigência de ANAC (2012b), deve ocorrer ao longo de toda a extensão da pista de pouso e decolagem a 3,0m do eixo, em ambos os lados, em frequências que variam de 12 a 36 meses, em função da quantidade de pousos diários.

No Aeroporto Internacional de Fortaleza a frequência de medição é de 24 meses. O que se apresentará a seguir - duas medições num intervalo de 12 meses - ocorreu em virtude da medição de 2013 ter apresentado valores de IRI muito superiores ao máximo recomendado. As medições foram realizadas nos meses de julho de 2013 e de 2014 .

Um equipamento do tipo perfilômetro inercial a laser, constituído de um sistema de medição de perfis longitudinais, que realiza suas medições com o auxílio de medidores de distância, de aceleração vertical, de deslocamento e de velocidade, sem contato (a laser), foi utilizado para a realização das medições. Esse equipamento é auxiliado por um microprocessador para gerenciamento e envio dos dados a um computador portátil, em tempo real, através de uma porta USB. Os dados de IRI são apresentados na Tabela 6. O valor máximo de IRI exigido por ANAC (2012b) é de $1,0 \mathrm{~m}$ para cada extensão de $500 \mathrm{~m}$ da pista em estudo $(1,0 \mathrm{~m} / 500 \mathrm{~m})$. 
Tabela 3. Dados de coeficiente de atrito 2013 Coeficiente de Atrito - 2013

\begin{tabular}{c|c|c|c|c|c|c|c|c}
\hline \multirow{2}{*}{$\begin{array}{c}\text { Trecho da pista } \\
(\mathbf{k m})\end{array}$} & \multicolumn{9}{|c|}{ Lado Esquerdo } & \multicolumn{4}{c}{ Lado Direito } \\
\cline { 2 - 10 } & Fev & Mai & Ago & Nov & Fev & Mai & Ago & Nov \\
\hline $0-0,5$ & 0,72 & 0,67 & 0,70 & 0,70 & 0,72 & 0,68 & 0,72 & 0,72 \\
\hline $0,5-1,0$ & 0,77 & 0,76 & 0,71 & 0,75 & 0,75 & 0,72 & 0,75 & 0,85 \\
\hline $1,0-1,5$ & 0,79 & 0,76 & 0,77 & 0,76 & 0,76 & 0,77 & 0,76 & 0,86 \\
\hline $1,5-2,0$ & 0,75 & 0,76 & 0,71 & 0,73 & 0,72 & 0,72 & 0,73 & 0,77 \\
\hline
\end{tabular}

Tabela 4. Dados de coeficiente de atrito 2014

\begin{tabular}{c|c|c|c|c|c|c|c|c}
\hline \multicolumn{9}{c}{ Coeficiente de Atrito - 2014 } \\
\hline \multirow{2}{*}{$\begin{array}{c}\text { Trecho da pista } \\
(\mathbf{k m})\end{array}$} & \multicolumn{9}{c|}{ Lado Esquerdo } & \multicolumn{4}{c}{ Lado Direito } \\
\cline { 2 - 10 } & Fev & Mai & Ago & Nov & Fev & Mai & Ago & Nov \\
\hline $0-0,5$ & 0,67 & 0,80 & 0,63 & 0,62 & 0,66 & 0,74 & 0,64 & 0,57 \\
\hline $0,5-1,0$ & 0,73 & 0,82 & 0,83 & 0,63 & 0,76 & 0,77 & 0,70 & 0,64 \\
\hline $1,0-1,5$ & 0,74 & 0,84 & 0,88 & 0,67 & 0,80 & 0,77 & 0,88 & 0,67 \\
\hline $1,5-2,0$ & 0,70 & 0,79 & 0,81 & 0,64 & 0,72 & 0,76 & 0,80 & 0,65 \\
\hline
\end{tabular}

Tabela 5. Média dos dados de coeficiente de atrito 2013 e 2014

\begin{tabular}{c|c|c|c|c}
\hline \multicolumn{5}{|c}{ Coeficiente de Atrito $-\mathbf{2 0 1 3}$ e 2014 } \\
\hline \multirow{2}{*}{$\begin{array}{c}\text { Trecho da pista } \\
(\mathbf{k m})\end{array}$} & Lado Esquerdo & Lado Direito & Lado Esquerdo & Lado Direito \\
\cline { 2 - 5 } & 0,70 & 0,71 & 0,68 & 0,65 \\
\hline $0-0,5$ & 0,75 & 0,77 & 0,75 & 0,72 \\
\hline $0,5-1,0$ & 0,77 & 0,79 & 0,78 & 0,78 \\
\hline $1,0-1,5$ & 0,74 & 0,74 & 0,74 & 0,73 \\
\hline $1,5-2,0$ & &
\end{tabular}

\section{ANÁLISE E DISCUSSÃO DOS RESULTADOS}

De um modo geral, observa-se que todos os parâmetros avaliados possuem valores menores em 2014 quando comparados aos valores obtidos em 2013, o que pode indicar um desgaste da superfície do revestimento da pista devido às operações de pousos e decolagens, às condições climáticas e ao envelhecimento natural dos materiais ao longo do tempo.

Todos os trechos analisados estão com macrotextura e coeficiente de atrito acima dos níveis mínimos estabelecidos em ANAC (2012a) e IRI acima de $1 \mathrm{~m} / 500 \mathrm{~m}$, que é o limite máximo recomendado. ANAC (2012a) recomenda o valor mínimo da profundidade da macrotextura $0,60 \mathrm{~mm}$ e o valor mínimo para o coeficiente de atrito 0,43. Diante deste cenário, pode-se afirmar que a pista em estudo possui uma adequada drenagem superficial (devido à macrotextura), uma satisfatória aderência pneu-pavimento (condição garantida pelo coeficiente de atrito), mas desfavorável conforto ao rolamento (gerado pelo IRI).

Outra comprovação geral feita diz respeito à dispersão entre os dados, sobretudo com relação à macrotextura e aos coeficientes de atrito obtidos no ano de 2014 quando comparados àqueles obtidos em 2013. Isso, porém, não se pode afirmar para os valores de IRI, que seguiram praticamente a mesma tendência entre os anos para todas as medições e trechos avaliados.

Quando se visualiza os gráficos da Figura 1 e 2 percebe-se, de maneira geral, a superfície do revestimento da pista é levemente mais homogênea no ano de 2013 quando comparado à superfície existente em 2014, sobretudo no que diz respeito ao coeficiente de atrito (Figura 1). O gráfico da Figura 1 foi elaborado com as médias dos coeficientes de atrito.
Tabela 6. Dados de irregularidade longitudinal 2013 e 2014

\begin{tabular}{l|c|c|c|c}
\hline \multicolumn{4}{c}{ Irregularidade Longitudinal - 2013 e 2014 } \\
\hline \multirow{2}{*}{$\begin{array}{c}\text { Trecho da } \\
\text { pista }(\mathbf{k m})\end{array}$} & \multicolumn{2}{c}{ Lado Esquerdo } & \multicolumn{2}{c}{ Lado Direito } \\
\cline { 2 - 5 } $\mathbf{J u l} / \mathbf{2 0 1 3}$ & $\mathbf{J u l} / \mathbf{2 0 1 4}$ & $\mathbf{J u l} / \mathbf{2 0 1 3}$ & $\mathbf{J u l} / \mathbf{2 0 1 4}$ \\
\hline $0-0,5$ & 3,19 & 3,16 & 3,11 & 3,12 \\
\hline $0,5-1,0$ & 3,46 & 3,26 & 3,10 & 3,10 \\
\hline $1,0-1,5$ & 3,78 & 3,66 & 3,01 & 2,99 \\
\hline $1,5-2,0$ & 2,98 & 2,84 & 2,74 & 2,47 \\
\hline
\end{tabular}

Quando se visualiza os gráficos da Figura 1 e 2 percebe-se, de maneira geral, a superfície do revestimento da pista é levemente mais homogênea no ano de 2013 quando comparado à superfície existente em 2014, sobretudo no que diz respeito ao coeficiente de atrito (Figura 1). O gráfico da Figura 1 foi elaborado com as médias dos coeficientes de atrito.

No gráfico da Figura 2 verifica-se praticamente o mesmo comportamento observado para os valores de IRI, com destaque para o lado direito (LD) que sempre apresentou valores menores quando comparados aqueles obtidos no lado esquerdo (LE) da mesma, para os dois períodos avaliados.

No Aeroporto Internacional de Fortaleza, a remoção do acúmulo de borracha na pista de pouso e decolagem ocorre a cada 180 dias. Essa atividade foi realizada pelo processo de hidrojateamento a alta pressão, nos meses de maio e novembro, no trecho inicial (nos primeiros $500 \mathrm{~m}$ ), sempre antecedendo as medições da macrotextura e do coeficiente de atrito.

Para o ano de 2014, as medições de macrotextura nos meses de remoção da borracha acumulada foram todas superiores àquelas obtidas durante os meses anteriores, sendo registrada a maior diferença (de $0,20 \mathrm{~mm}$ ) no mês de novembro, lado direito. Esses aumentos nos valores de macrotextura podem indicar um desgaste da superfície do revestimento causado pelo processo de remoção do acúmulo de borracha. Tal operação ocasiona uma exposição maior da 


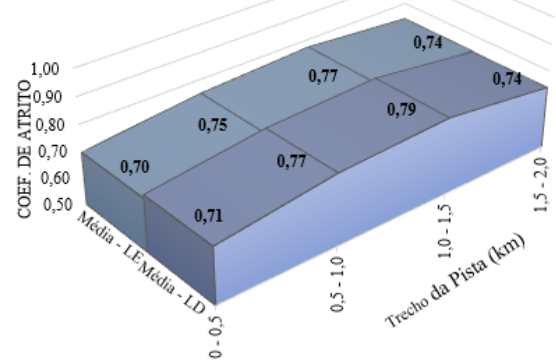

(a)

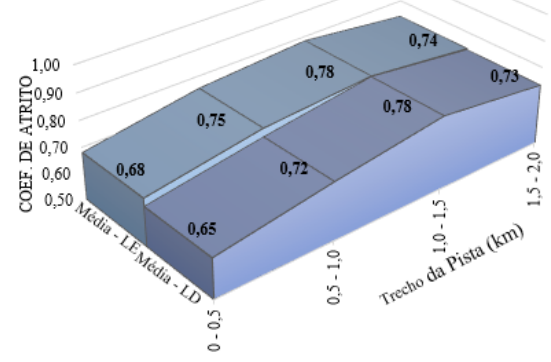

(b)

Figura 1. Superfícies da pista em função do coeficiente de atrito, em 2013 (a) e 2014 (b) IRI - 2013 IRI - 2014

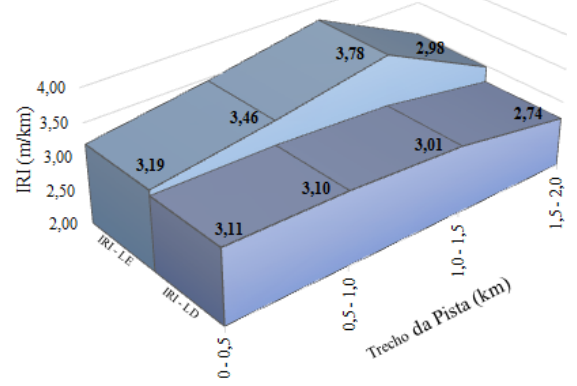

(a)

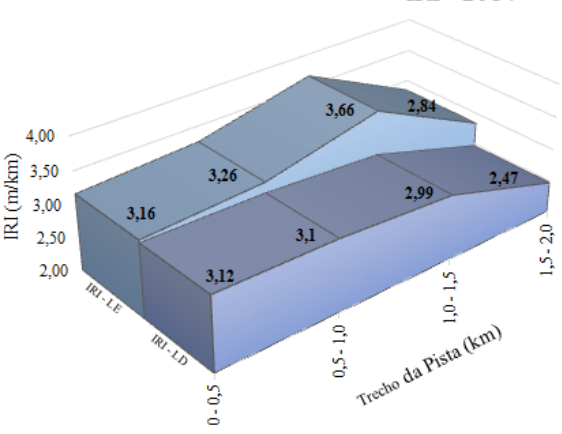

(b)

Figura 2. Superfícies da pista em função do IRI, em 2013 (a) e 2014 (b)

textura do revestimento, devido à retirada da borracha acumulada, permitindo uma maior profundidade média da macrotextura.

Quando se trata do coeficiente de atrito, em 2013, observam-se reduções no mês de maio e nenhuma alteração em novembro, para as medições realizadas em ambos os lados da pista. Para o ano de 2014, contrariamente ao ano anterior, observou-se aumento dos coeficientes de atrito no mês de maio e reduções no mês de novembro, que registrou o menor de todos os valores.

Diante do exposto, pode-se deduzir que o processo de remoção do acúmulo de borracha não proporcionou homogeneidade da rugosidade do revestimento da pista de pouso e decolagem do aeroporto em estudo, já que os dados dos parâmetros não tiveram o mesmo comportamento nas medições realizadas, apesar de garantirem que estão acima dos mínimos recomendados.

Os menores valores de macrotextura estão localizados no trecho final da pista em estudo, ou seja, entre 1,5 e $2,0 \mathrm{~km}$. Os dados obtidos entre 2,0 e $2,5 \mathrm{~km}$, não expostos neste trabalho, também indicam uma continuidade de baixos valores de macrotextura para o final da pista. Mesmo diante dessa constatação, os valores são superiores a $0,60 \mathrm{~mm}$.

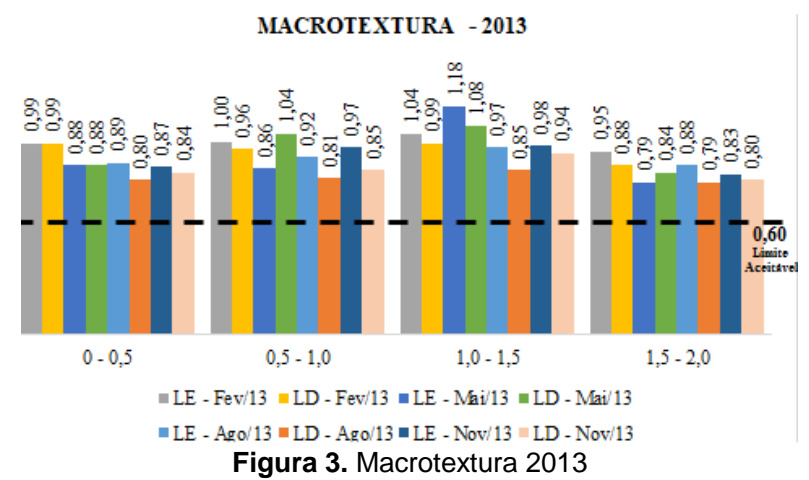

No início da pista observam-se os menores valores de coeficiente de atrito, o que pode promover uma maior dificuldade ou restrição para as aeronaves iniciarem a aceleração nas decolagens ou de manter um primeiro contato dos pneus com o revestimento durante os pousos, especialmente no primeiro trecho, onde fica a zona de toque. Isso é observado para os dois anos de medições.

Os maiores valores para a macrotextura $(1,32 \mathrm{~mm}) \mathrm{e}$ o coeficiente de atrito $(0,88)$, assim como o maior valor de IRI $(3,78 \mathrm{~mm} / 500 \mathrm{~m})$, estão localizados no trecho entre 1,0 e $1,5 \mathrm{~km}$ da pista, o que corresponde ao segmento central quando considerada sua extensão total. Desse modo, constata-se um comportamento de tendência divergente desse segmento da pista de pouso e decolagem do aeroporto internacional de Fortaleza.

As Figuras 3 e 4 mostram a evolução da macrotextura para os anos de 2013 e 2014. Pela disposição dos gráficos das Figuras 5 e 6 é possível analisar essa evolução do coeficiente de atrito para cada um dos quatro trechos da pista em estudo, percebendo-se uma dispersão dos dados desse parâmetro ocorrida para o ano de 2014, quando comparados aos obtidos em 2013, bem como o destaque para o trecho compreendido entre 1,5 e $2,0 \mathrm{~km}$ da referida pista.

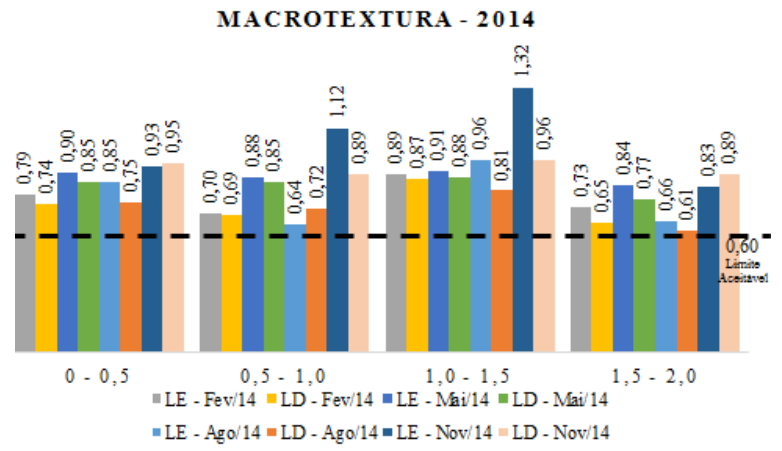

Figura 4. Macrotextura 2014 


\section{EVOLUÇÃO COEFICIENTE DE ATRITO - 2013}

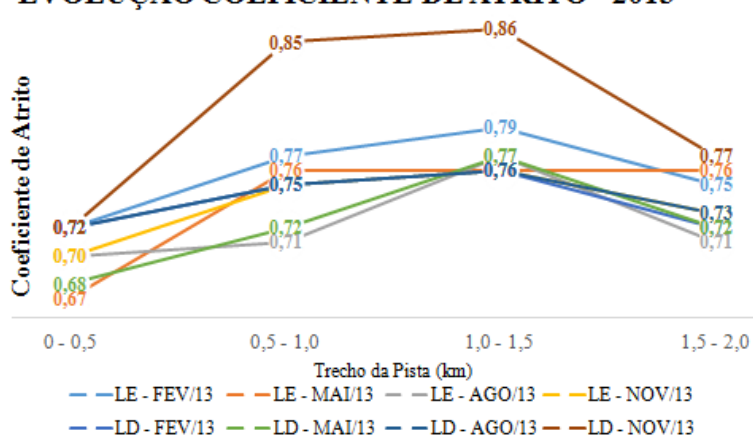

Figura 5. Evolução coeficiente de atrito - 2013

\section{EVOLUÇAO COEFICIENTE DE ATRITO - 2014}

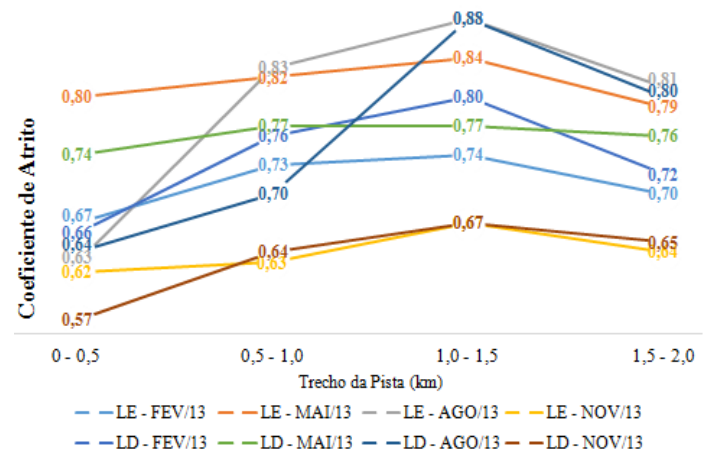

Figura 6. Figura 5. Evolução coeficiente de atrito - 2013

EVOLUÇÃO IRI - 2013/2014

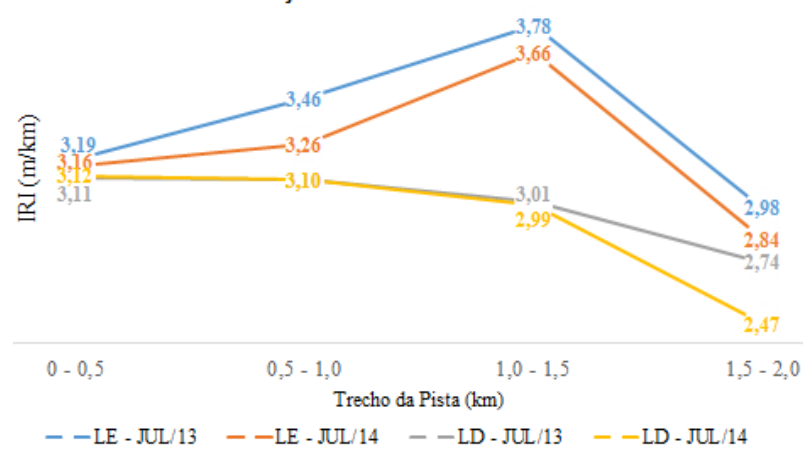

Figura 7. Evolução IRI entre os anos de 2013 e 2014

A Figura 7 apresenta a evolução do IRI entre os anos de 2013 e 2014. Pela análise do gráfico dessa figura é possível observar que o lado esquerdo da referida pista apresenta valores maiores que do lado direito, além de tornar possível concluir que a irregularidade dessa pista diminuiu de 2013 para $2014 \mathrm{em}$ ambos os lados.

\section{CONCLUSÕES}

Em pistas de pouso e decolagem, o papel desempenhado pela textura superficial dos revestimentos é de caráter bastante relevante, especialmente diante de precipitações pluviométricas intensas ou quando da presença de contaminantes, pois assegura às aeronaves as condições de controle direcional em solo e a frenagem adequada. Condições insatisfatórias de macrotextura e de coeficiente de atrito reduzem a resistência à derrapagem das aeronaves levando-as à elevação dos índices de acidentes e incidentes.
O IRI, como indicador das condições operacionais das pistas de pouso e decolagem, é recente no Brasil. Sua aplicação ocorreu no final de 2012, para cumprimento obrigatório por parte dos operadores de aeródromos. Ocorre que o emprego desse parâmetro como de avaliação funcional das superfícies das pistas e de qualidade de rolamento das aeronaves pode não ser o ideal, pois sua concepção foi feita com base em irregularidades constatadas em pavimentos rodoviários. Em pavimentos aeroportuários, as aeronaves possuem sistemas de pneus e amortecimentos projetados para absorver os grandes impactos das operações de pouso.

Isso é uma função bastante diferente do sistema de amortecimento dos veículos, que foi concebido para proporcionar maior conforto aos passageiros durante as viagens nas rodovias. Por isso, o valor máximo exigido de IRI $(2 \mathrm{~m} / \mathrm{km})$ pode não representar diferenças significativas na qualidade do rolamento de pavimentos aeroportuários.

Os valores obtidos para os três parâmetros indicam, neste estudo, o que se deduz empiricamente quando se analisa a rugosidade de superfícies de revestimentos flexíveis: quanto mais rugosa a superfície do revestimento, melhores condições de drenagem superficial são promovidas (macrotextura), maiores valores de aderência são atingidos pelo contato pneu-pavimento (coeficiente de atrito) e menor é o conforto à qualidade de rolamento das aeronaves (IRI).

\section{AGRADECIMENTOS}

Os autores agradecem à Empresa Brasileira de Infraestrutura Aeroportuária (INFRAERO), no Aeroporto Internacional Pinto Martins, pela disponibilização dos dados.

\section{REFERÊNCIAS}

ANAC (2012a) Resolução No. 236, de 05 de junho de 2012. Agência Nacional de Aviação Civil. Secretaria de Aviação Civil.

ANAC (2012b) Regulamento Brasileiro de Aviação Civil RBAC no. 153, de 30 de dezembro de 2012. Agência Nacional de Aviação Civil. Secretaria de Aviação Civil.

Almeida, L. C. Avaliação da irregularidade longitudinal das pistas de pouso e decolagem de aeroportos brasileiros. 2015. 96f. TCC (Graduação) - Curso de Engenharia Civil, Centro de Ciências Tecnológicas, Universidade de Fortaleza, Fortaleza, 2015.

Boeing, 2014. Statistical Summary of Commercial Jet Airplane Accidents Worldwide Operations 1959 - 2012. Disponível em http://www.boeing.com/news/techissues/pdf/statsum.pdf, Acesso em 18 maio 2015 .

CENIPA (2015) Panorama Estatístico da Aviação Civil Brasileira. FCA 58-1. Ministério da Defesa. Comando da Aeronáutica. Centro de Investigação e Prevenção de Acidentes Aeronáuticos. Brasília, DF.

FAA (1997) Measurement, construction and maintenance of skid-resistant airport pavement surfaces. Advisory Circular - AC 150/5320-12C. Federal Aviation Administration. United States Department of Transportation. Washington, DC. 
FAA (2009) Airport Pavement Design and Evaluation. Advisory Circular - AC 150/5320-6E. Federal Aviation Administration. United States Department of Transportation. Washington/DC.

FAA (2014) Guidelines and Procedures for Maintenance of Airport Pavements. Advisory Circular - AC 150/5380-6C.

Federal Aviation Administration. United States Department of Transportation. Washington, DC.

Fonseca, O. A. (1990) Manutenção de Pavimentos de Aeroportos. Diretoria de Engenharia da Aeronáutica. Divisão de Estudos e Projetos de Infra-Estrutura. Ministério da Aeronáutica. Brasília, DF

Gillespie, T. D., SAYERS, M. W.; SEGEL, L. (1980) Calibration and Correlation of Reponse-Type Road Roughness Measuring Systems. National Cooperative Highway Research Program Report, Washington, n. 228, 88p.

ICAO (2002) Manual de servicios de aeropuertos. Parte 2. Estado de la superficie de los pavimentos. Cuarta edición. Organización de Aviación Civil Internacional. Lima, Peru.

ICAO (2004) Annex 14 to the Convention on International Civil Aviation. Aerodrome Design and Operations. Volume I.. 4th Edition. International Civil Aviation Organization. Montreal, Canada.

ICAO (2012) Runway Surface Condition Assessment, Measurement and Reporting. Cir 329. AN/191. Internacional Civil Aviation Organization. Montreal, Canada.

Kazda, A.; Caves, R. E. (2007). Airport Design and Operation (2nd Edition). Publisher Elsevier Science. New York, NY DOI: $10.1108 / 9780080546438$

Oliveira, F. H. L. (2009) Proposição de Estratégias de Manutenção de Pavimentos Aeroportuários Baseadas na Macrotextura e no Atrito: Estudo de Caso do Aeroporto Internacional de Fortaleza. Dissertação de mestrado. Departamento de Engenharia de Transportes. Universidade Federal do Ceará. Fortaleza, CE.

Oliveira, F.H.L; Nobre Júnior, E.F. (2009) Acúmulo e remoção de borracha em pavimentos asfálticos do Aeroporto Internacional de Fortaleza. XXIII Congresso de Pesquisa e Ensino em Transportes - ANPET. Vitória/ES.

PIARC (1987). Permanent International Association of Road Congresses Report of the committee on surface characteristics.18th World Road Congress,Brussels, Belgium

Sayers, M. W.; Karamihas, S. M. (1998) The Little Book of Profiling. Basic Information about Measuring an Interpreting Road Profiles. The Regent of the University of Michigan. 98p.

Sun, L., Kan, S.; JI, Y. (2004) Evaluation and Rehabilitation Models of Airport Pavement Management System: a case study of Shanghai Pudong International Airport. In: 6th International Conference on Managing Pavements. TRB Committee AFD10 on Pavement Management Systems. Brisbane, Queensland, Australia

Thom, N. (2010) Principles of Pavement Engineering. Thomas Telford Publishing Ltd. London. DOI: 10.1680/ppe.58538

TRANSPORT CANADA (2004) Aerodrome Safety Circular. ASC 2004-024. Appendix A - Guidelines Respecting the Measurement, Evaluation and Maintenance of Airfield Pavement Surface Friction. Government of Canada. 